\title{
Achieving Client-Centered Collection Development in Small and Medium-Sized Academic Libraries
}

\section{Bart Harloe}

This article presents a model for collection development appropriate for libraries whose primary purpose is to support undergraduate education. After a discussion of the organizational prerequisites for client-centered collection development in small and medium-sized academic libraries, a step-by-step approach to the implementation of such a program is sketched. It is argued that academic libraries following this strategy can create a decision-making structure whereby important collection development initiatives are taken by the library with the advice and consent of the teaching faculty.

\section{"An intractable, apparently eternal problem plagu- ing academic libraries is the unevenness of faculty commitment to collection building. ${ }^{\text {"1 }}$-Mary Biggs}

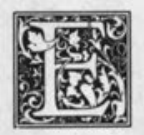

xhortations to small and medium-sized academic libraries to follow the lead of the large research libraries and move from faculty-driven acquisitions process to a library-centered collection development program appear frequently in library literature. ${ }^{2}$ It is argued that those academic libraries whose primary mission is undergraduate instruction need to take control of the library materials budget, assume responsibility for selection and take a more rational approach to collection management and development. For example, it was recently argued in College $\mathcal{E}$ Research Libraries that college libraries in particular should adopt this model and establish library authority over the selection process: "The first step must be the aban- donment of the department apportionment process.,"3

This article proposes that a collection development strategy that focuses on budget authority and allocation structure is likely to cause unnecessary conflict. A more positive approach involves the creation of a comprehensive collection development program which, in turn, creates a different context for selection decision making. The logic of the model proposed here-client-centered collection development-leads inevitably toward a selection process in which the library makes decisions with the advice and consent of the faculty. The focus is not on the materials budgets per se, but rather on the quality of the decision-making process for selection.

This article is addressed to librarians who want to improve collection development, but in a way that does not involve confrontation with the teaching faculty. Other, somewhat overlapping audiences 
are librarians who work in colleges with collections in the $100,000-300,000$ volume range and those in libraries with collections in the $300,000-800,000$ volume range. It is addressed to librarians who find the Standards for College Libraries relevant in judging how well they are supporting their institutional mission, and those whose libraries have less than the "magic million" in acquisitions budgets, or that serve institutions with strong or even lingering liberal arts traditions. $\mathrm{Fi}$ nally, it is addressed to those who are willing to consider new ways of doing things and to take the strategic initiative in pursuit of new organizational ventures.

\section{THREE BASIC MODELS OF SELECTION IN ACADEMIC LIBRARIES}

Let us begin by imagining an organizational continuum with three basic points of reference (see figure 1). On one end is the historical model of selection. Its key characteristic is the faculty-driven acquisition process; book budgets are allocated to academic departments, where the bulk of orders originate as faculty requests. On the other end is the research model of se- lection, whereby a highly organized and mostly library-directed collection development organization, characterized by a library staff of subject bibliographers and part-time selectors, is largely responsible for carrying out a complex acquisition program.

The third model, located in the center of the continuum, is a shared authority model; although the library is responsible for the collection development program, faculty participate actively in the selection process.

Over the last ten years, academic librarians have significantly increased their control of the selection process. They have been especially successful within research libraries. While these developments enhance the position of some librarians and improve collection management, they also create a challenge for librarians in small and medium-sized colleges that are clustered toward the historical model end of the continuum. Given a small professional staff and a tradition of faculty control of acquisitions, how do you move toward a more library-controlled effort? Other questions arise in medium-sized ac-

THREE MODELS DF SELECTION

IN ACADEMIC LIBRARIES

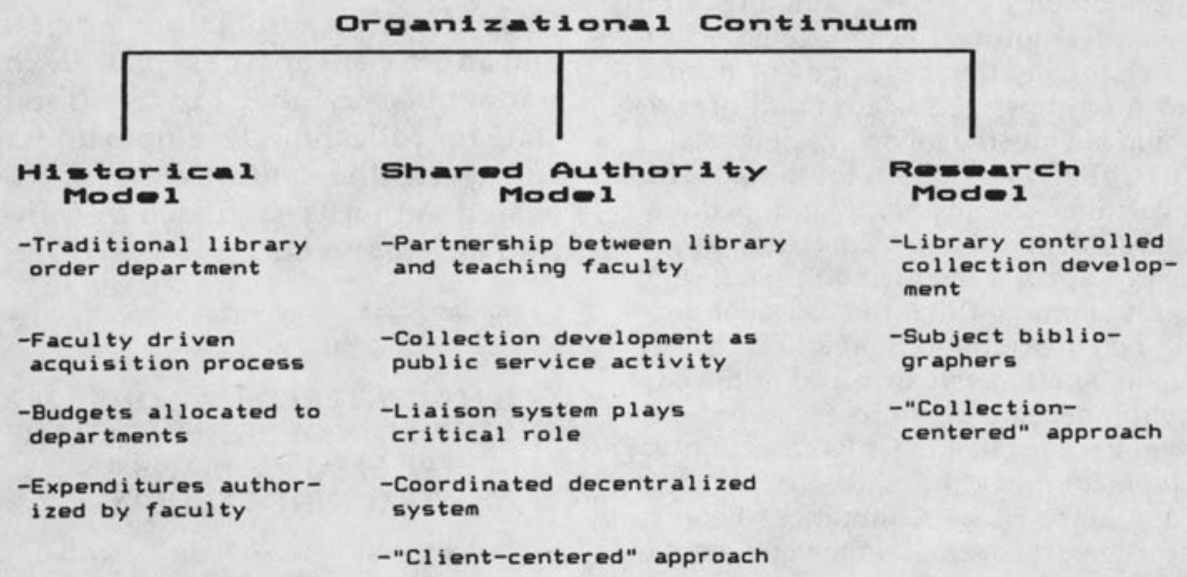

Organizational Charactoristics

FIGURE 1

Three Models of Selection in Academic Libraries 
ademic libraries that support both undergraduate and graduate education: What is the best way to organize a collection development program? Is the research model appropriate? If so, can it be implemented?

To answer these questions, the basic components of a collection development organization will be sketched and a more specific shared authority model-clientcentered collection development-appropriate for small and medium-sized academic libraries will be outlined. A realistic strategy for phasing in a client-centered program will then be presented.

\section{CLIENT-CENTERED COLLECTION DEVELOPMENT}

What are the signs of an effective collection development organization in an academic library? William Hannaford lists five key indicators:

1. Written policies covering collection development activities

2. Control of and responsibility for the materials budget by the library

3. Presence of someone in the library who is, in effect, the chief collection development officer

4. Librarians who select, weed, evaluate, budget and allocate

5. The presence of a collection development organization, e.g., faculty liaison ${ }^{5}$

In addition to these generic organizational prerequisites, a client-centered approach to collection development in small and medium-sized academic libraries should include the following elements:

1. Collection Development for Instruction-In most small and mediumsized academic libraries the collection primarily supports instruction; therefore, it is very important that the collection process be curriculum-centered. The library should be intimately involved in the curriculum development process in order to have effective planning in its collection development program. $^{6}$

2. Library Serials Committee-Because of the impact of serials on the budget, it is important that small and medium-sized academic libraries have a well-organized serials management program. Ideally, the serials committee should be composed of librarians and faculty and it should select and review serial collections on a regular basis.?

3. Automation Program-The library should have an automation program that allows it to produce collection management data, whether it be a new acquisitions list produced by its bibliographic utility or a budget/vendor report produced by its automated acquisitions system. Recent microcomputer developments now make it possible for small and medium-sized academic libraries to have sophisticated collection management programs. $^{8}$

4. Approval Plan-A well-designed approval plan, based upon a core collection concept of the library's program, is essential to the success of a client-centered collection development program. This plan allows the library to manage the selection process effectively and, if developed correctly, may eventually lead to library control of the materials budget. ${ }^{9}$

5. Client-Centered Liaison Structure[An effective automation program and an efficient approval plan are important because they can free library staff for collection development liaison work, the central element in a shared authority approach to collection development.]

\begin{abstract}
"An effective automation program and an efficient approval plan are important because they can free library staff for collection development liaison work, the central element in a shared authority approach to collection development."
\end{abstract}

\section{CLIENT-CENTERED LIAISON WORK: THE DIVISION OF RESPONSIBILITIES BETWEEN LIBRARIANS AND TEACHING FACULTY}

The liaison structure would be a dual approach including librarians assigned to academic departments to facilitate the collection development process and classroom faculty liaisons who represent the academic units. This structure com- 
bines the best bibliographic expertise available in the library with the best subject expertise of the teaching faculty. The liaison system would serve as a communication link, allowing the teaching faculty to communicate its concerns regarding the collections and the library, in turn, to notify interested parties of changing policies and procedures related to collection development. In order to be effective, the clientcentered liaison system must be coordinated from the library, and the librarians must be the prime movers in this decentralized network.

It is essential that the library be involved in the development of new academic courses and programs. Librarians working within a liaison structure would typically be involved in the curriculum development process. They would also review orders from academic departments in order to keep abreast of current faculty interests. They could work with the approval plan, developing profiles in cooperation with teaching faculty, review approval books and notification slips, and keep faculty informed of recently ordered materials. Librarians would be serving as academic problem-solvers.

Faculty should participate in the collection development process. Teaching faculty library liaisons would be responsible for representing current faculty concerns about the collections as they relate to the instructional needs of their departments. Typically, they could also review approval shipments and facilitate new serials requests to the library's serials committee. While the library should be flexible about the nature and extent of the role faculty liaisons play, there must be documented agreement on the division of responsibilities and the mutual expectations of the parties involved.

\section{A STRATEGY FOR CHANGE: MOVING TOWARD A CLIENT-CENTERED COLLECTION DEVELOPMENT PROGRAM}

The first step is to determine whether or not the library needs a fully developed collection development program. The library might begin a collective self-analysis by answering the following questions:
1. Is the library typically the last unit on campus to be informed of new courses and new academic programs?

2. Are there chronic complaints from faculty and students about either the quantity or quality of the collection?

3. Is the materials budget in a constant state of crisis?

4. Are serials consuming an everincreasing portion of the library's materials budget?

5. Is there confusion and/or conflict about the perceived role of the collections in supporting both instruction and research?

\section{SELF-STUDY। CONSULTATION PROCESS}

The answers to some of the above questions may be obvious, directing the library toward action, based upon a generally accepted perception of its ability to meet its collection goals. But assuming a need to validate these subjective perceptions, how might the library gather data to confirm initial impressions? There are three basic options for dealing with this preliminary needs analysis:

1. Small academic libraries might consider a self-study manual that has been explicitly developed for smaller academic libraries: Measuring the Book Circulation Use of a Small Academic Library Collection: A Manual. ${ }^{10}$

2. Medium-sized academic libraries might consider conducting a collection analysis project with the Office of Management Services, Association of Research Libraries. ${ }^{11}$

3. Rather than pursuing a self-study approach, small or medium-sized academic libraries might choose to consult an outside collection development expert who would make a site-visit. This approach is generally less time-consuming and more flexible than the self-study and the exact nature and extent of the consultation can be determined by the library. ${ }^{12}$

During this initial self-study/ consultation process, the library should address "enabling questions," in addition to the five questions posed above.

1. Does the library have the critical mass necessary to launch and implement 
a full-fledged collection development program? In other words, do the librarians support the effort and is the teaching faculty open to changing their relationship with the library?

2. What is the state of the library's automation systems and what computerized applications can be made toward collection management/development?

3. How extensive is the library's bibliographic instruction program and what kind of outreach does it involve?

4. Does the library have effective resource sharing arrangements? ${ }^{13}$

5. Is there an existing liaison network, formal or informal, that could be expanded and strengthened in order to function as a collection liaison structure?

Answers to these two sets of questions should determine whether or not the library moves ahead to establish a collection development program. Obviously, local circumstances will dictate the outcome. As the self-study will quickly demonstrate, much will depend upon the library staff's attitude toward the change and the efforts it would require on the existing collection development structure. Thus, if there is no faculty discontent, if the acquisitions program is viewed as adequate, if users perceive the collections as strong, if there is no budget crunch, and if an informal communications network effectively addresses collection needs, then library staff may well conclude from the selfstudy/consultation process that it is not necessary to push ahead with a more formal collection development program.

\section{PHASING IN A CLIENT-CENTERED COLLECTION DEVELOPMENT PRO- GRAM}

For purposes of this analysis, however, let us assume that, as a result of the above efforts, a library determines that it needs a more organized approach to collection development. Let us also assume that the library wants to set up a client-centered program and that there is some support both inside and outside the library for such an effort. The gradual implementation of such a program would include five phases.

\section{First Phase}

The first order of business is to establish a collection development committee and chairperson. This committee will provide an internal library forum for the discussion of issues related to collection management and development. It is important that the chair of this group assume responsibility for coordinating collection development activities and schedule regular meetings with agendas. In this way, issues can be addressed on an ongoing basis.

“Once a library collection development group has been organized, the library should move very rapidly to appoint collection development liaisons, both teaching faculty and librarians."

Once a library collection development group has been organized, the library should move very rapidly to appoint collection development liaisons, both teaching faculty and librarians. Initial discussions should focus on the roles and responsibilities of the two. Once consensus on this division of labor has been reached, the responsibilities should be articulated and documented.

The library should also consider during this first phase initiating an approval plan selection process. Approval plan vendors should be invited to the campus for presentations to an audience that would include teaching faculty. A very focused dialogue between the library and the faculty about the role of the collections in supporting instruction and research should result from the presentation. For example, the concept of a core collection will emerge from discussion of the process of creating an approval plan profile.

At this point, a pilot approval plan should be established, requiring the allocation of part of the materials budget. Even a small approval plan will have an impact, and the subject areas chosen and funding allocated should be carefully de- 
termined, taking into consideration which departments might best work with this acquisitions method.

Finally, the library should decide whether to enlist the services of a collection development consultant. Careful consideration should be given to the role of a consultant as well as to the expectations of such a visit. For example, the library may decide that an orientation and training program for both library staff and teaching faculty could serve a useful purpose and also advance the library's agenda, and a consultant's guidance would prove valuable in establishing such a program.

\section{Second Phase}

It is now time to appoint a serials selection and review committee, which includes representatives from the library and from the faculty. The committee's first task should be to write a serials selection policy statement, the drafting of which should provoke a lively debate about the role of the journal collections in supporting the instructional and scholarly activities of the academic community. Once the serials committee has completed a draft, it is critical that the document be widely circulated throughout academic departments. The liaison system can facilitate the process of distribution and discussion. The college or university library committee would be responsible for its final approval.

In this phase, the library should also initiate a trial approval plan in selected subject areas. Key academic departments should participate both in the profiling process and in the screening of approval books received. Although librarians, too, should take part in this review process, it is especially important that teaching faculty evaluate the profile during the first year of operation. As a result of this kind of faculty participation, two things should happen: (1) the approval profile will be further defined and refined; and (2) the faculty will gradually gain confidence in the approval plan as a collection development tool.

During the second phase, the library should launch liaison outreach activities with various academic units, especially with those involved in the new approval plan. Topics of discussion during this period of development might include: (1) the role of the library in the curriculum development process; (2) the need for, and the purpose of, collection policy statements; and (3) the role of the new serials committee and especially the procedures for requesting a new journal. Topics such as these will encourage full discussion and dialogue including both theoretical concerns and practical aspects of implementation.

\section{Third Phase}

By this phase, librarian liaisons are ready to play a greater role in the selection process. They should be involved in the review of approval books for their respective academic subject areas. Another way to strengthen the library's role in the selection process is to initiate librarian review of firm orders coming from faculty in the academic departments. While this review may serve primarily to maintain current awareness, these librarians will eventually gain confidence in their ability to anticipate the collection needs of their academic departments.

During this phase of the new program approval plan performance should be evaluated. Informal discussions with faculty and librarians about the effectiveness of the approval plan should be supplemented by checking appropriate bibliographies covering the subject areas concerned. If the approval program is effective, it should be expanded to cover all core areas of the curriculum. Needless to say, it is critical to consult faculty and reach a true consensus before the approval program is extended.

Expansion of the approval plan will require the allocation of a large portion of the acquisitions budget. The approval plan vendor should provide one-year budget estimates, based upon the new, more comprehensive profile. With this information, the library can project spending needs for a new acquisitions program in the next budgetary year.

The library should also allocate a budget for new serial titles. This allocation will de- 
pend, in turn, upon the current status of the book budget vis-a-vis the commitment to ongoing serial subscriptions. Once this is accomplished, the serials committee can begin to receive requests for new serial titles. The serials committee may also want to begin a discussion on procedures for reviewing established subscriptions as well as approving new ones.

\section{Fourth Phase}

The basic structure for selection decision making should be in place by this phase. The liaisons have been appointed and mutual responsibilities worked out to the satisfaction of both parties. The approval plan pilot program, after a period of testing, has been expanded to cover the core curriculum areas. The serials committee has met and made decisions on the first round of requests for new journals. The serials committee may even have begun to review current subscriptions with a view toward identifying for cancellation littleused, very expensive titles that no longer meet the instructional/scholarly needs of the college or university.

As the new collection development program continues to evolve, the library may want to analyze its automated systems with a view toward using already existing collection management information to further enhance the program. If the library does not have an automated acquisitions system, it may want to contact its bibliographic utility and find out what services and products it can provide to support the program. For example, a new holdings list distributed to members of the liaison network can serve to clarify the advantages of the new approach for developing the library's collections.

Another way to solidify further the new collection development structure is to explore library resource-sharing optionslocal, regional, and national. Indeed, if the library can demonstrate that it is effectively pursuing a resource-sharing program that increases access to external resources, it may be able to make a successful case for a core-collection approach at the local level.

\section{Fifth Phase}

Based upon experience with the ap- proval plan and intensive discussion throughout the liaison network, it should now be possible to draft, and then circulate for approval, collection policy statements. Because the library will have gained practical collection development experience by this phase, the process of writing, discussing, and approving such statements will not be just a theoretical exercise. In fact, the approval plan profile can serve as a kind of conspectus during the development of the collection policy statements.

"Thus, the conversation between the librarians and the faculty is no longer focused on dollars, but rather on the collections, and how those collections support the academic programs offered to students by the faculty."

Finally, as the library continues to monitor approval plan performance and to emphasize the importance of faculty participation in the overall selection process, it may want to move toward a subject allocation structure for the materials budget. By now the library has demonstrated its commitment to improving the acquisitions process by creating a collection development program that places the emphasis on quality selection decisions rather than on money. The theme of the library at this point should be: "Tell us what you need and we will try to obtain it," within the context of those policies and procedures that now guide the collection development process. Thus, the conversation between the librarians and the faculty is no longer focused on dollars, but rather on the collections, and how those collections support the academic programs offered to students by the faculty.

\section{Schedule for Implementation}

The time frames for the five phases described above will depend upon local circumstances. Some libraries may be able to move quickly, others more slowly, depending upon previously existing collection development activities and experi- 
ence. The important thing is to have a plan, flexible yet concrete, and to move steadily toward the next set of objectives. It is important to continue to involve teaching faculty every step of the way and to gain university or college administrative support. The library committee can be an important ally in this process.

When the library implements a new collection development program, it is important to monitor progress and to evaluate the success of the program as it evolves. We need to keep in mind the concrete outcomes that we are seeking and the objective indicators that will allow us to say that we are achieving client-centered collection development. ${ }^{14}$

\section{CONCLUSION ACHIEVING CLIENT-CENTERED COLLECTION DEVELOPMENT IN ACADEMIC LIBRARIES}

Heretofore, the collection development function in academic libraries has usually been performed by a staff of full-time subject bibliographers, in some areas supplemented by a small number of part-time selectors who may have other primary duties (such as reference or cataloging). ${ }^{15}$ While this approach to collection development has appeared to work in mid-sized to large research libraries, it would also appear to be inappropriate for small to medium-sized academic libraries whose primary mission is to support undergraduate instruction. ${ }^{16}$

"This approach to collection development assumes that the 'clientcentered library' is a real possibility in today's small and medium-sized academic libraries."

The organizational model described in this essay-client-centered collection development-is a highly decentralized scheme that requires all, or almost all, librarians to do some collection development liaison work. The emphasis is not so much internal, on the collections and the needs and requirements of research programs, but rather external, on the users, the instructional programs, and the curriculum.

In fact, this approach to collection development assumes that the "client-centered library" is a real possibility in today's small and medium-sized academic libraries. ${ }^{17}$ A number of features of this type of management system should make it attractive to small and medium-sized academic libraries. For one thing, it is a collegial model, emphasizing horizontal decision making and teamwork. In many small and medium-sized academic libraries, the collegial tradition is still strong and the client-centered approach might be seen as an organic, evolutionary step. ${ }^{18}$ The client-centered library is based upon the notion that the librarian is a multitalented professional who might be expected to perform more than one role in the organization. Thus, librarians in this kind of organization might be expected to do cataloging and reference work, as well as instruction and collection development. It is true that advanced subject background would certainly facilitate the collection development function. However, because the primary emphasis is on liaison work per se, it is expected that the librarians involved would, as a matter of course, become familiar over time with the teaching needs and research interests of their primary clientele: the students and faculty.

Once a program such as this is put into place, a library could approach with confidence the question recently posed by Ernest Boyer: "Does the library's acquisitions policy resist domination by narrow scholarly interests, serving also undergraduate education?'"19 I believe that small and medium-sized academic libraries are in an excellent position to resist and overcome those whom Oscar Handlin calls the hyperspecialists, "who increasingly populate the faculties" and who "usually value only the materials they themselves use and regard alien collections as distracting drains upon resources. ${ }^{\prime 20}$ But progress will be made only if the small and medium-sized academic libraries take an active stance and if the librarians involved pursue an assertive, well-planned collection development strategy in the years ahead. 


\section{REFERENCES AND NOTES}

1. Mary Biggs, "Sources of Tension and Conflict Between Librarians and Faculty," The Journal of Higher Education 52:188 (Mar./Apr. 1981).

2. See, for example, William A. Miller and Stephen Rockwood, "Collection Development from a College Perspective," in College Librarianship, ed. William Miller and Stephen Rockwood (Metuchen, N.J.: Scarecrow, 1981), p.135-46.

3. Charles A. Gardner, "Book Selection Policies in the College Library: A Reappraisal," College \& Research Libraries 46:145 (Mar. 1985).

4. ACRL Ad Hoc College Library Standards Committee, "Standards for College Libraries, 1986," College \& Research Libraries News 47:189-200 (Mar. 1986). The intended audience then, is that group of institutions defined by the Carnegie Foundation for the Advancement of Teaching as Liberal Arts Colleges I and II and Comprehensive Universities and Colleges I and II. For the most recent version of the Carnegie Classifications, see "Carnegie Foundation's Classification of More than 3,300 Institutions of Higher Education," The Chronicle of Higher Education 33:22-30 (July 8, 1987). For an interesting application of the Carnegie Classification categories to undergraduate institutions where a distinctive type of scholarship takes place, see Kenneth P. Ruscio, "The Distinctive Scholarship of the Selective Liberal Arts College," The Journal of Higher Education 58:205-22 (Mar./Apr. 1987).

5. William E. Hannaford, Jr., "Collection Development in Ten Small Academic Libraries: A Report of the Council on Library Resources" (ERIC Document Reproduction Service, ED190074 1979), p.4-5. See also Hannaford's essay entitled "Collection Development in Private Colleges," in Library Resources for College Scholars: Transactions of a Conference Held at Washington and Lee University ed. Robert E. Dunford (Lexington, Va.: Washington and Lee University, 1980), p.13-17.

6. For a good example of library integration into the curriculum development process, see Judith Lee Hunt, "Integrating Library Resources into Instructional Design," in Options for the 80s: Proceedings of the 2nd National Conference of the ACRL ed. Michael Kathman and Virgil Massman (Greenwich, Conn.: JAI Press, 1982), p.227-37.

7. The best approach to this organizational problem is described by Jane E. Fowler in "Managing Periodicals by Committee," Journal of Academic Librarianship 2:230-34 (Nov. 1976). See also ACRL College Library Information Packet Committee, Periodicals in College Libraries (Clip Note \#8) (Chicago: American Library Assn., 1987). The latter publication contains many examples of periodicals policies and procedures currently in use in college libraries.

8. John C. Calhoun and James K. Brachen describe how one college library utilized its automated acquisitions system for collection management purposes in "Automated Acquisitions and Collection Development in the Knox College Library," Information Technology and Libraries 1:246-56 (Sept. 1982).

9. For a case study illustrating how one library effectively managed the transition to an approval plan, see Daniel Gore, "Adopting an Approval Plan for a College Library: The Macalister College Experience" in To Know a Library: Essays and Annual Reports, 1970-1975 (Westport, Conn.: Greenwood, 1978), p.22-27.

10. Mary Kane Trochim, with Arthur Miller, Jr., and William M. K. Trochim, Measuring the Book Circulation Use of a Small Academic Library: A Manual (Washington, D.C.: Association of Research Libraries, Office of Management Studies, 1985).

11. For a capsule description of the Office of Management Services/Association of Research Libraries' Collection Analysis Project, see Scott Bennett, "Current Initiatives in Collection Management," Journal of Academic Librarianship 10:257-61 (Nov. 1984).

12. The use/abuse of consultants in academic libraries is explored in S. Michael Malinconico, "The Use and Misuse of Consultants, " Library Journal: 558-60 (March 15, 1983); see also Duane Webster and John Lorenz, "Effective Use of Library Consultants," Library Trends: 345-62 (Winter 1980).

13. This is a very important question that must be addressed during the implementation of a clientcentered collection development program. See Robert F. Munn, "Collection Development vs. Resource Sharing: The Dilemma of the Middle-Level Institution," Journal of Academic Librarianship 8:352-53 (Jan. 1983); and Bernard H. Holicky, "Collection Development vs. Resource Sharing: The View from the Small Academic Library," Journal of Academic Librarianship 10:146-47 (1984).

14. Mary J. Cronin, Performance Measurement for Public Services in Academic Libraries (Washington, D.C.: Association of Research Libraries, Office of Management Studies, 1985) p.22-23.

15. Collection Development Organization and Staffing in ARL Libraries: SPEC Kit 131 (Washington, D.C.: Association of Research Libraries, Office of Management Studies, Systems and Procedures Ex- 
change Center, 1987), p.1. See also Jeanne Sohn, "Collection Development Organizational Patterns in ARL Libraries," Library Resources \& Technical Services 31:123-34 (April/June 1987).

16. For a comprehensive literature review that covers both small and medium-sized academic libraries, see Mickey Moskowitz, "Collection Development and the College Library: A State of the Art Review," Collection Building 6:5-10 (Summer 1984); see also Bonita Bryant, "Collection Development Policies in Medium-sized Academic Libraries," Collection Building 2:6-28 (Fall 1980); and finally, for an overview of organizational issues in collection development, see Bryant, "The Organizational Structure of Collection Development," Library Resources \& Technical Services 31:111-22 (April/June 1987).

17. Charles Martell, The Client-Centered Library: An Organizational Model (Westport, Conn.: Greenwood, 1983).

18. Martell, The Client-Centered Library, p.67-89. For a case study of how one medium-sized academic library implemented a "matrix model," see Joanne R. Euster and Peter Haikalis, "A Matrix Model of Organization for a University Public Services Division," in Academic Libraries: Myths and Realities: Proceedings of the Third National Conference of the Association of College and Research Libraries ed. Suzanne C. Dodson and Gary L. Menges (Chicago: ACRL, 1984), p.357-64.

19. Ernest L. Boyer, College: The Undergraduate Experience in America (New York: Harper 1987), p.292.

20. Oscar Handlin, "Libraries and Learning," American Scholar, 56:211 (Spring 1987). 